\title{
Wuhan International Horse Racing Festival to Raise the Overall Influence of Wuhan City
}

\author{
Li Yaonan \\ Wuhan Business University \\ Wuhan Hubei province 400056
}

\author{
Hu Rui \\ Tianjin University of Sport \\ Tianjin 300000 \\ 654921475@qq.com
}

\begin{abstract}
With the continuous development of Chinese economy, to promote the steps of city development, to expand the city's image and to enlarge urban influence force, holding an influential event has become an important force to promote Wuhan urban development. Based on sports such as economics, information economics and the horse racing industry economics as the theoretical basis, by the method of documentation, qualitative analysis and logical analysis, discussion and research on Wuhan racing festival to raise the overall strength of Wuhan city.
\end{abstract}

Keywords - International horse racing festival; Wuhan; Urban comprehensive influence

\section{INTRODUCTION}

Sporting events has a great significance for the host city. Sports event is a link to the host city economy, culture, and many aspects, such as geographical environment, humane environment involves many factors in the city. It is in the process of host; Coordination affects can mobilize social resources, many industries, promote the development of industry, promote the smooth completion of the event, and also pulls each industry's production efficiency. Sporting events held on the host city of the residents also make a difference. Wuhan racing festival held in Wuhan for many years, deeply rooted in the hearts of the people, widely known, competition mechanism is more mature. Wuhan racing festival held in Wuhan for many years, deeply rooted in the hearts of the people, widely known, competition mechanism is more mature. Build the development of Wuhan city core competitiveness, maintained good momentum of the competition. Horse racing festival in Wuhan, can attract large Numbers of tourists come to Wuhan, the central city with a long history. Since Wuhan is located in the inland of China, is China's largest inland sea transport hub, has long been known as its "thorough fares of nine provinces", from Beijing, Shanghai, Guangzhou of China's large convenient geographical neighbors, traffic is very convenient. A large number of population, also in Wuhan transportation infrastructure and services put forward higher requirements, a bigger test are given. [1]This is a difficult problem, also big opportunity of the development of Wuhan city. Horse racing event in relatively special sporting events, in mainland China, Wuhan racing festival is alone. Due to the unique advantages of horse racing event, more can strengthen the city's profile, pull the urban development and upgrade the residents, expand the urban economic structure, promoting the comprehensive influence of the city.

\section{Horse-RACing CURRENT SituAtion OF THE DEVELOPMENT OF DOMESTIC AND ABROAD}

\section{A. Development Status of Horse Racing in other Countries}

Britain is the birthplace of modern British horse racing, with its unique way to a sports betting and the perfect combination, and this model to the whole world. The horse is the quintessence of Chinese culture, is an industry is also a kind of culture. The British horse racing event held a long history, has been affected alone is not a city, but for the country, is a symbol of a cultural symbol.

The United States as the world's largest economy, horse racing industry is very advanced, both in quantity and quality of horses in the world leading. The rich and interesting event type, horse breeding technology, excellent quality and wide racing event influence, let the United States on the way ahead. As a horse racing industry sport in Australia, a popular Australian Jockey. One of the largest in the world, the number of horses is only in the United States. At the same time, the United Arab Emirates, Japan, South Korea, Singapore and other countries of the horse racing industry development more and more.

The development of horse racing industry brought these countries and regions of the huge economic efficiency and the influence of tells us that the success of horse racing event, the formation of the racing industry chain, can not only improve the influence of the city, promote the development of city economy, but also from the aspects of driving city development, held an inestimable race.

\section{B. Domestic Urban Horse Racing Development Situation}

Racing to the city of Hongkong into a positive effect is obvious; the racing industry has become Hongkong in addition to tourism and free trade industry, another focus of the Hongkong horse industry. Smokeless industry is an important factor of prosperity and development of the city. On the one hand, Hongkong will invest heavily in Hongkong's public infrastructure reconstruction, directly to promote Hongkong's economic growth rate; on the other hand, horse racing has driven the development of Hongkong tourism industry, promote the injection of foreign capital. The history of Hongkong club is quite deep, and it has penetrated into every place in Hongkong society. The people of Hongkong cannot do 
without an important symbol of the modern metropolis of Hongkong horse racing [2].

But, Chinese has not yet opened commercial horse racing, so in size, economic strength, horse racing industry is far from Chinese as developed as Hongkong. However, along with our country city development is getting better, and city level events held in the process more and more quickly, the city in order to improve the comprehensive influence of city, enhance the brand image of the city, competing for large equestrian events. Not only first-tier cities, second tier, the right to host the three line of the city are also actively strives for the event.

\section{Wuhan International Horse Racing Festival}

China Wuhan international horse racing festival is a large city festivals of Wuhan municipal people's government hosted, by Wuhan municipal sports bureau, Wuhan what lake district people's government, the east group to undertake, the golden October of 2003, the first China Wuhan racing festival held in Wuhan Oriental success. For decades, Wuhan harvest will host a horse racing festival every year, to 2016, has held the $14 \mathrm{Th}$. Wuhan international horse racing festival speed racing open tube being separated, event, organized by Wuhan people's government of Wuhan sports competition regulation, and technical supervision of Chinese equestrian association is responsible for the whole event [3]. In the sixth events, sports lottery for the first time to enter the mainland racetrack, which means that China's first, approved by the general administration of sport of horse racing perennial tournament officially settled in Wuhan.

\section{WUHAN INTERNATIONAL HORSE RACING FESTIVAL ON THE IMPACT OF THE DEVELOPMENT OF THE CITY OF WUHAN}

\section{A. To Enhance the Development of Wuhan Tourism Industry}

For tourists, the tourism attraction is the guiding elements of tourism destination. These elements can attract tourists to stimulate internal demand for tourism, the tourism behavior. Foreign scholars put forward the tourism attraction: the city through the promotion of tourism related information has the attraction, tourists and tourism destination together, to stimulate people's needs so, travel behavior into reality, when the three was established at the same time, "attract". Wuhan International Horse Racing Festival located in Wuhan held so far, there have been fourteen, every year to watch the games, teams and tournament workers from all over the world. This event will constitute the so-called "brigade Tour attraction ", success oriented Wuhan city become a tourist destination. The Wuhan racing festival every tournament audience of nearly ten thousand people, the twelfth Wuhan International Horse Racing Festival, the two day competition attracted nearly twenty thousand viewers, record the number of hit games over the years the ceremony. So the number of people, for the city of Wuhan tourism development of the industry, is a huge stimulus. The increase in the number of tourist hotels catering drives the development of the retail industry.

At the Wuhan International Horse Racing Festival, Wuhan city Star hotel Tourist Hotel, catering industry have launched a series of activities such as the Wuhan horse racing festival to attract customers, many foreign competitors and tourists and local residents in Wuhan city to the east city to watch the game, making the most of a single daily catering revenues have increased rapidly, the surrounding hotel occupancy rate increased significantly. City around the large supermarket retail sales also rose [4].

\section{B. To Drive the Media, the Rapid Development of the Communications Industry}

Sports media friend hook and attention economy, promote the development of the attention economy directly. People to understand sports, or go to stadium watch the game directly, or through sporting events on TV, or through books, newspapers and magazines. Wuhan international horse racing festival is no exception, major portals and television were on real-time events, television broadcast sports advertisements use to obtain revenue, vendors can improve product visibility; expand sales and more profits for [5].

\section{On the Impact of Public Infrastructure in Wuhan}

Sports development cannot do without the construction of stadiums and surrounding the construction of transportation. Wuhan International Horse Racing Festival to carry out, first requires huge investment, the construction of large-scale racing venues, but also related to the construction of the city infrastructure. This role for the city's material culture construction plays a quite large. Wuhan International horse racing festival site, located in the eastern city of gold and Silver Lake area in Wuhan City, the racecourse covers an area of about 1000000 square meters, the radiation from the East Matriarchs economic benefits to the surrounding areas, the city transportation infrastructure construction of Wuhan gold and Silver Lake area developed rapidly, around the horse, Wuhan City A set of city infrastructure, including city roads, communications, hydro power facilities, greening, Wuhan metro line six, Metro Line seven is the development of [6]. The city infrastructure construction in the east city station, will be directly or indirectly connected with the development direction of Wuhan city planning and construction, promote the rapid development of Wuhan the construction of city planning. Through racing venues, transportation construction, landscape construction and improve the city's international reputation. Brings new changes for Wuhan city buildings and facilities

\section{Enhance the Image of the City of Wuhan; Improve the Cohesion of the People}

Horse racing festival held in Wuhan for many years, the expansion of Wuhan city popularity, brand construction of Wuhan culture played an important role, making Wuhan has been become a country of "horse race" [7]. Every horse racing festival held in Wuhan by the unprecedented attention, many viewers to viewing greatly improve the image of the city of Wuhan, set up the Wuhan urban business card of "horse race of city". Wuhan welcomes the visitors coming from all parts of the world, and for local residents to various forms of etiquette education. Not only promote the development of local culture and education, but also to the communication of different cultures. Wuhan international horse racing festival this large international sports event, the citizens are proud, the large-scale 
sports event, the more people pride and sense of belonging, the stronger, greatly enhance the cohesion.

\section{CONCLUSION}

Wuhan international horse racing festival has been held in Wuhan for many years which help to raise publicity of Wuhan and won the reputation of "city of horse racing”. At the same time, Wuhan international horse racing festival help Wuhan establish culture brand, promote the development of Wuhan economic and society as well as respond to 'Wuhan construction program for national center city' issued by Wuhan municipal government. From the economy view, holding an international horse racing can obviously improve urban infrastructure like stadium construction, municipal transportation construction, and urban postal and telecommunication system construction. Meanwhile, the hosting of horse racing festival can contribute the development of sports industry and further the development of tourism, catering and hotel industry. Also it will help accelerate the development of electronic media industry and other industries. From social aspect, since urban culture brand has been set up by holding this international festival, it is helpful for government to gather public cohesion.

\section{REFERENCES}

[1] Aaron Cohen.Values and Commitment: A Test of Scherzos Human Values Theory among Arab Teachers in Israel [J].Journal of Applied Social Psychology.2010 (8)

[2] Wu Jia, Tu Weidong. Horse racing and the world economy research society of Hongkong [J]., 1991. (In Chinese)

[3] Ceng Qingshan. Influence of high speed railway construction on the tourism of Wuhan city circle, Huazhong Normal University, 2013. (In Chinese)

[4] Miao Kegui. Build Wuhan tourism industry cluster brand thinking, Century Bridge, 2007. (In Chinese)

[5] Fan Qiguo, Liu.21 century China's sports media industry research, sports science and technology, 2006. (In Chinese)

[6] Huang Haiyan, Lou Shi Yu. Domestic and international sports event industry development [J]. sports scientific research, 2010 (1):1-2. (In Chinese)

[7] China Tourism Statistics Yearbook. (2001-2011) [Z]. Beijing: China Tourism Publishing House. (In Chinese) 